\title{
DATA ACQUISITION, MANAGEMENT AND EVALUATION FOR STONE CONSERVATION PROJECTS WITH DIGITAL MAPPING
}

\author{
DIPL.-ING. GUNNAR SIEDLER ${ }^{1}$, DIPL.-INF. (FH) SEBASTIAN VETTER ${ }^{1}$, JENS \\ KAMINSKY ${ }^{2}$ \\ ${ }^{1}$ fokus GmbH Leipzig \\ Lauchstädter Straße 20, 04229 Leipzig, Germany \\ e-mail: Siedler@fokus-GmbH-Leipzig.de,web: www.fokus-GmbH-Leipzig.de \\ ${ }^{2}$ Restauratorische Bauplanung Jens Kaminsky \\ Wartburgstr. 11, 08525 Plauen, Germany \\ e-Mail: mail@jenskaminsky.de,web: www.restaurierungsplanung.de/
}

Keywords:Documentation, Conservation, Mapping, Object hierarchy, Photogrammetry, Laserscanning

Abstract. Several years of experience in heritage documentation have given a background to develop methods of digital photogrammetry and mapping. The outcome is the development of a mapping software over a period of 20 years.Main features of the software are image rectification, vector based mapping, quantity survey and data analysis. In Germany, it is mainly used in the field of stone conservation. Small projects can be processed as a single mapping project, whilst complex projects like a cathedral can be organised as a hierarchical project, with several mapping projects for individual object parts. Each mapped element can be connected with additional attributes. This allows visual analysis of mapping activities, quantities and attributes - like in a geographical information system (GIS) for conservators. Tools and procedures for efficient mapping are developed in close cooperation with conservators from different fields. It is shown how large stone objects can be managed efficiently with an example project from the field of natural stone. This applies to the overall data acquisition and data evaluation for condition analysis, conservation planning, accounting documentation and monitoring. Due to the advances in the fields $3 D$ laser scanning and digital photogrammetry within the past 5 years the R\&D project „PROQUATO" (2016 - 2018) was initiated by fokus GmbH Leipzig with the institute for photogrammetry and remote sensing of TU Dresden and Scan $3 D \mathrm{GmbH}$, Berlin. Project results for efficient data processing and functions for 3D mapping will be presented. Current developments deal with the fast processing of point clouds scanned by laser scanner for the use as reference for image rectification, deformation analysis and creation of section lines.

\section{DOCUMENTATION - TRUE TO SCALE IMAGE RECTIFICATION AND ORTHOGONAL PROJECTION}

\subsection{Definition of quality parameters - image scale / image resolution}

The required detail resolution (pixel size at the object) is reliant on the image scale / resolution as well as the metric accuracy and has to be specified depending on the task on the object. So the subsequent user (architect, planner, conservator) can process their own 
graphical / metrical evaluation and content interpretation in CAD or mapping software.
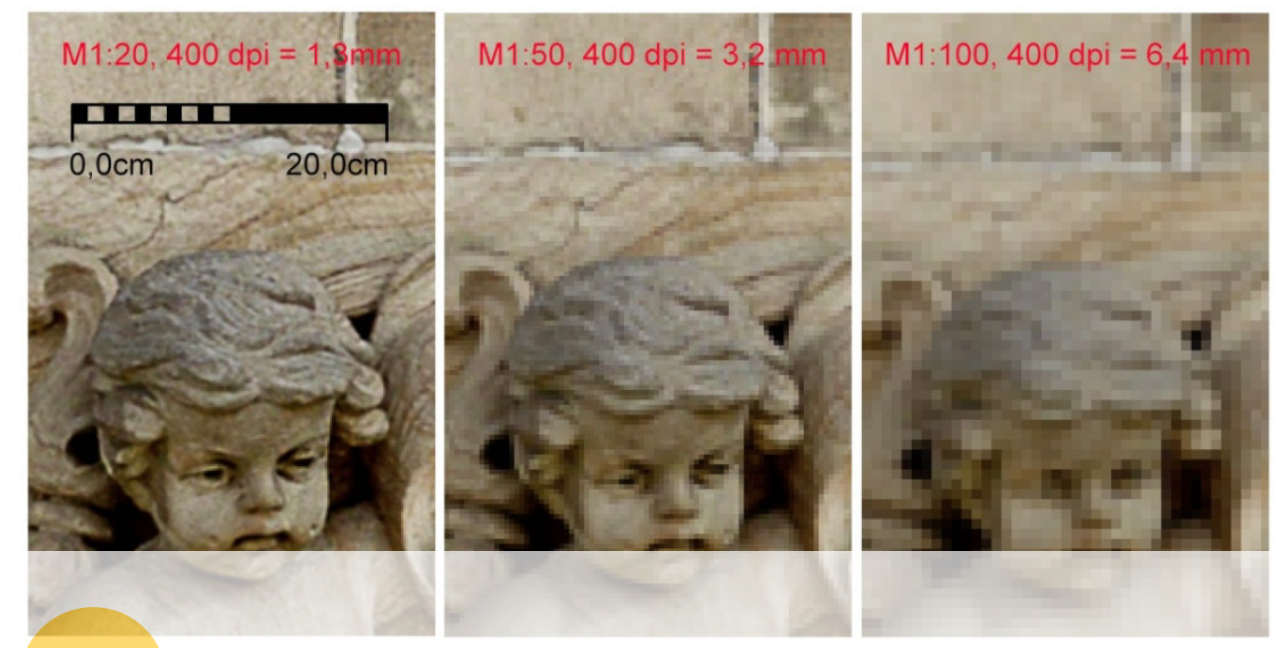

Fig. 1: Detail resolution depending on image scale 1:20, 1:50, 1:100 for 400 dpi image resolution

The required detail resolution is traditionally defined by image scale and resolution. For an image resolution of $400 \mathrm{dpi}$ ( 400 points per inch $=25.4 \mathrm{~mm}$ ) the point size is $0.06 \mathrm{~mm}$.

Multiplying the point size with the image scale provides the metric size of the pixel at the

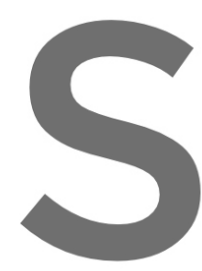

object, which means $0.06 \mathrm{~mm}$ for
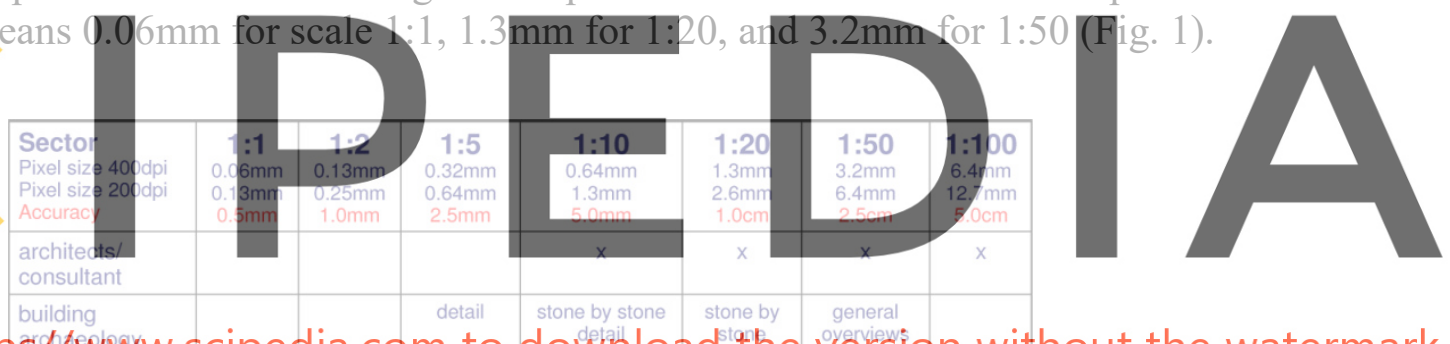

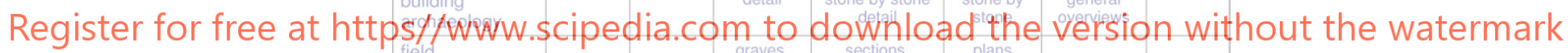

\begin{tabular}{|c|c|c|c|c|c|c|c|}
\hline archaeology & & & $\begin{array}{l}\text { gther, } \\
\text { details }\end{array}$ & $\begin{array}{l}\text { elevations } \\
\text { graves }\end{array}$ & pians & & \\
\hline Conservation & 1:1 & $1: 2$ & 1:5 & $1: 10$ & $1: 20$ & $1: 50$ & $1: 100$ \\
\hline stone & & & & $x$ & $\mathrm{x}$ & $\mathrm{x}$ & \\
\hline $\begin{array}{l}\text { wall painting / } \\
\text { stucco }\end{array}$ & & & $x$ & $x$ & $x$ & & \\
\hline $\begin{array}{l}\text { wood / objects } \\
\text { archaeology }\end{array}$ & & $x$ & $x$ & $x$ & & & \\
\hline $\begin{array}{l}\text { wall painting / } \\
\text { textile / paper }\end{array}$ & $x$ & $x$ & $x$ & $x$ & & & \\
\hline
\end{tabular}

Fig. 2: Overview for required detail resolution depending on application examples; Detail resolution (pixel size at the object) for $400 \mathrm{dpi}$ and $200 \mathrm{dpi}$; Evaluation accuracy depending on image scale (0,5mm x image scale); mural painting highlighted in red boxes [4]

The table shown in Fig. 2 displays evaluation scales, two quality levels (200 and 400 dpi) and the requirements for evaluation accuracy resulting from the image scale for different application examples. In general natural stone objects are processed for a scale 1:25 and 400dpi (1.6mm point size) or 1:50 and 400dpi (3.2mm point size), if lower quality is enough. For objects with higher levels of details or for sculptures a scale of 1:10 and $400 \mathrm{dpi}(0.6 \mathrm{~mm}$ point size) is used. 


\subsection{Evaluation methods}

Not every evaluation method is suited for each project. Dependent on the object surface (flat walls, vaults, ornaments) the suited method must be chosen.

2D image rectification allows mathematical transformation of $2 \mathrm{D}$ plane within the bundle of rays of one camera (central projection). The result is a true to scale image plan that allows measuring on one object plane.

An image can be rectified simply by geometry like rectangle, parallel lines (Fig. 3) or distance net. For complex objects, it is recommended to rectify images on the base of imported ground control points measured with totalstation.

In addition measuring of coordinates in the project based on CAD-drawing, image plan, ortho-projection is possible as well as the automatic image rectification of partial detail images by image matching.

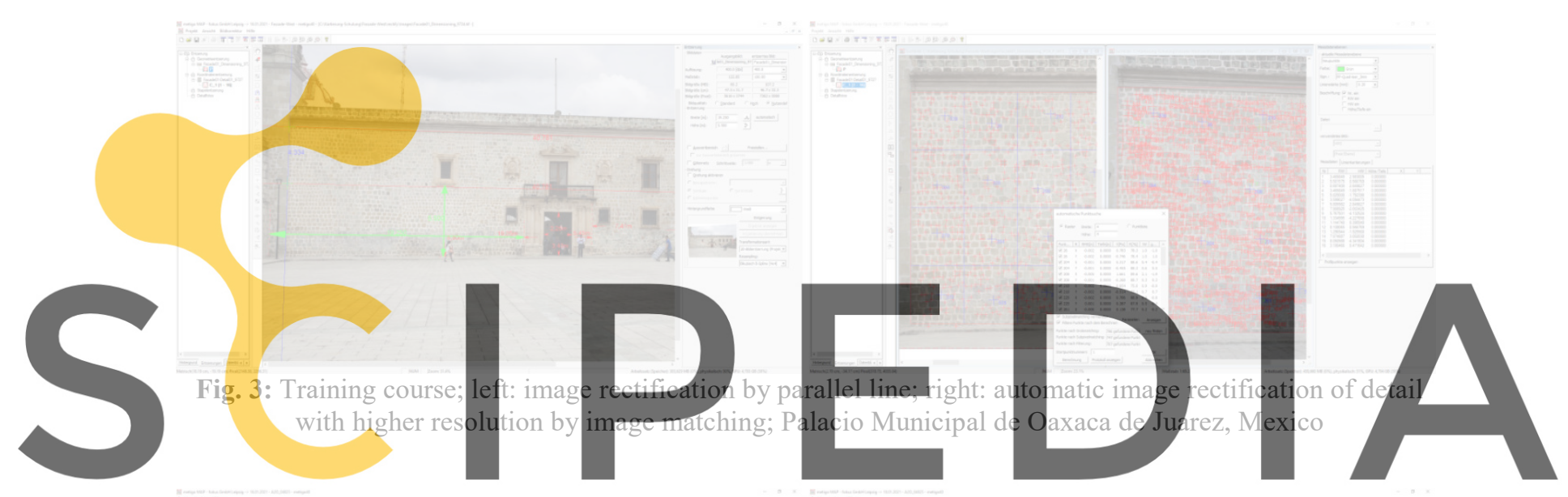

Register for free at https//www.scipedia.com to download the version without the watermark

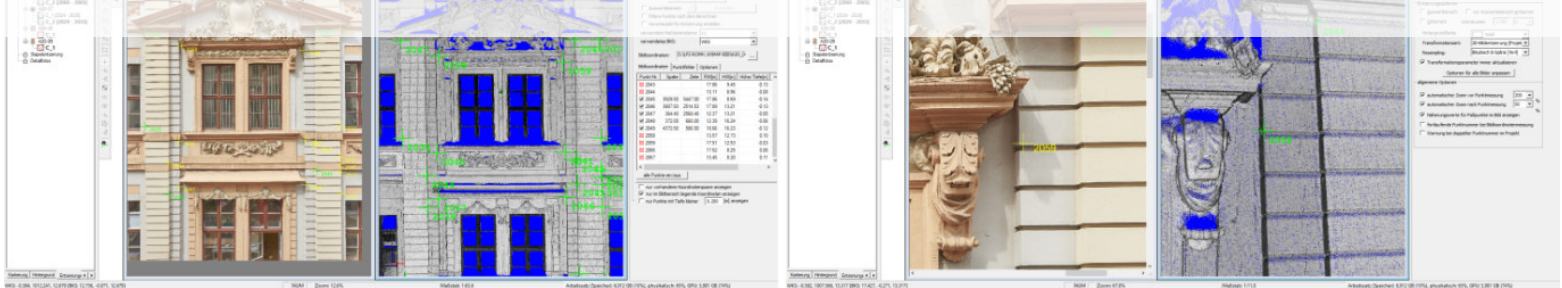

Fig. 4: rectification based on point cloud in two views; left: total image; right; detail from the image; Romanushaus, Leipzig, Germany

The 3D orthogonal projection always assumes the 3D recording of the object surface. The 3D data (point-cloud, textured surface model) are projected orthogonally onto a reference geometry (plane, cylinder, cone) [2]. The creation of 3D data can be done by digital photogrammetry (Structure from Motion - SfM) or terrestrial laser scanning (TLS). The result is a true to scale image plan (orthophoto), which allows measuring on all planes PARALLEL regarding the reference geometry. The orthophoto can be calculated by a textured surface model or by the combination of an orientated image and an untextured surface model (Fig. 5). 

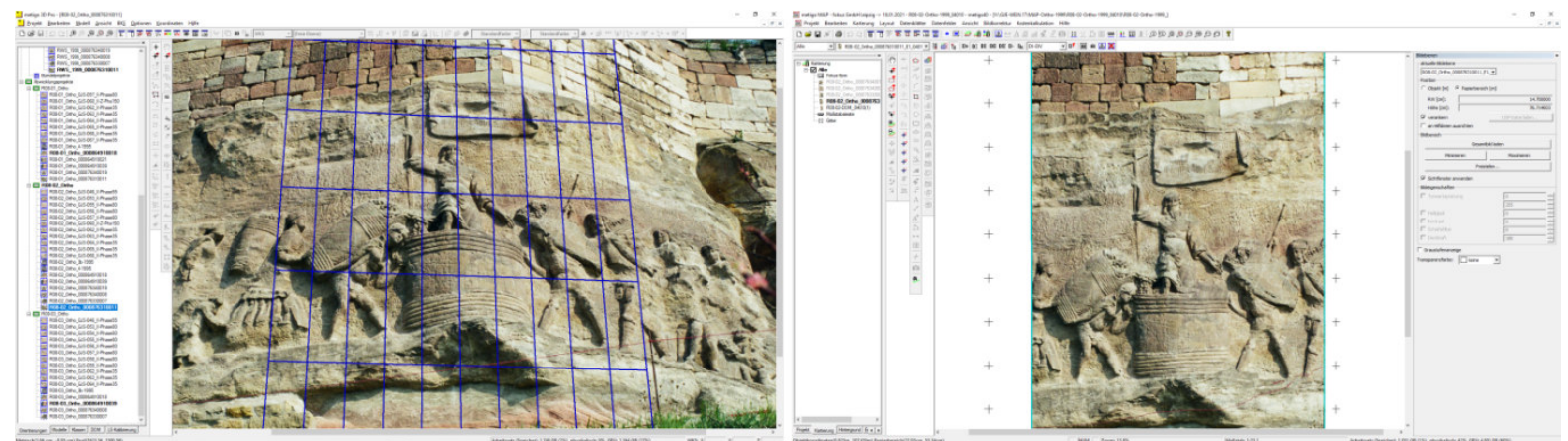

Fig. 5: orthogonal projection of an orientated image supported by a surface model; left: orientated image with projected plane; right: true to scale image plan in metigo ${ }^{\circledR}$ MAP; Stone Album, Großjena, Germany

3D object documentation is based on 3D recording of the object surface by point-cloud using TLS or SfM. In a second step the points are connected by triangulation to create a digital surface model (DSM). If necessary, the DSM is textured using orientated images. The result is a true to scale textured DSM that allows three dimensional measurements, creation of section and deformation analyses as well as creation of orthogonal projection onto several geometries.

For all these methods applies: A lack of good photography means a good result cannot be created. In our opinion, 2D-rectification is the cheapest method, which provides the highest image quality. 3D orthogonal projection is the most time expensive method, because image need to be orientated photogrammetrically and DSM need to be scanned or created by SfM. 2 PROJECT STRUCTURE-MAPPING PROJECT AND OBJECT HIIERARCHY
The mapping software metigo $($ MAP has been developed since the year 2000 to create digital, vector-based mappings including mass calculation. The mapping software metigo $\mathbb{R}$ MAP offers functions for creation of true to scale documentation, digital mapping analyses for free at https 1 www.scipedia.com to download the version without the watermark

\subsection{Miapping project}

The base for digital mapping are rectified images, CAD-drawings (DWG) or 3D-surface models (ortho-projection). For every topic (condition, material, measurement), a mapping class with a special type for area and line mapping, image and vector symbols or annotation and dimensioning have to be defined. Different mapping classes can be grouped within a mapping project to turn several mapping themes (e.g. conditions and damages, planning of measurements and invoicing) on or off.

For the final layout of the plans, there are several documentation classes like grids, scale bars, auxiliary lines and legends with integration of quantity surveys and analysis. (Fig. 6).

The extended group management is useful for the repeated use of class sets (loan, excavation layers, project phases). This structure of a mapping project (classes, groups, attributes, legends, title blocks etc.) can be reused in subsequent projects (import/export).

Areas and lines can be drawn with different vector based mapping tools like polygons and free hand lines, beziér lines (splines) and arcs, rectangles and circles, circle arc, as well as dimensioning functions for lengths and heights. Areas can be filled transparently. 
For editing lines, there are different CAD-commands such as extend, trim, align, mirroring and different modes for object snap. For editing outlines of adjacent areas and the integration of inclusions, there are several intersection functions. A large library with hatchings, line types, image and vector symbols as well as colour tables enables the user to define layouts of mapping classes. The user interface can be set up easily for work in office as well as for work on mobile mapping with tablet PC on site.

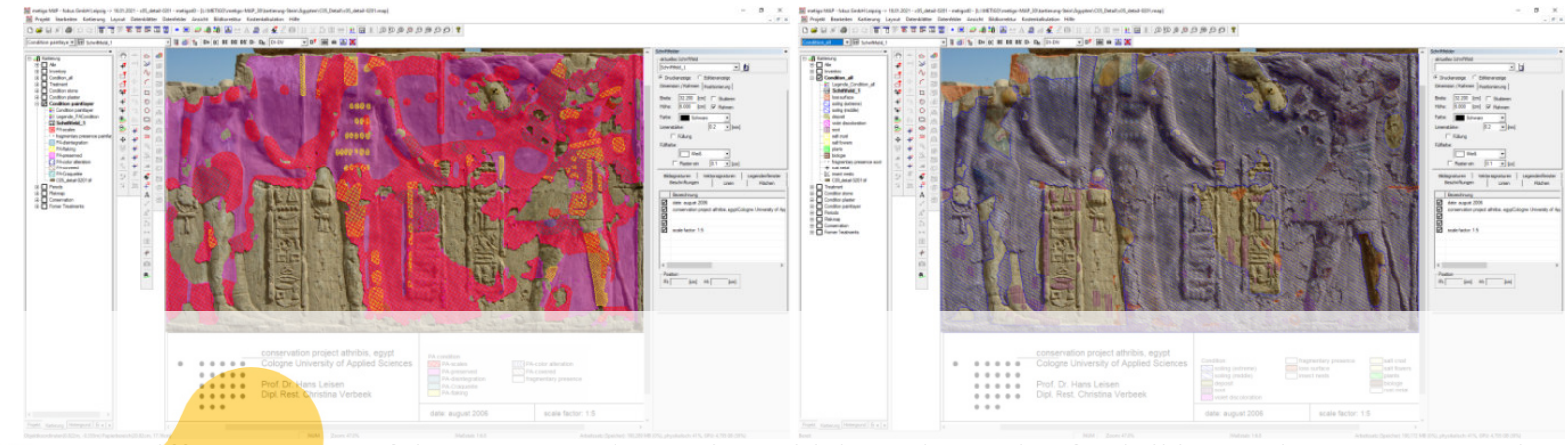

Fig. 6: Different groups of the same mapping project with legend; temple of Athribis at Sohag, Egypt;Mapping: Sabine Krause, Cologne.

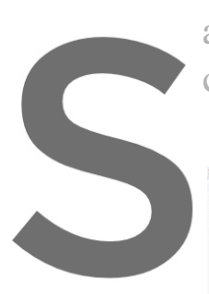

Every element can be sorted according to size ranges within a mapping class. Mapping activities, quantities class (stone, material

Register for free at https//www.scipedia.com to download the version without the watermark
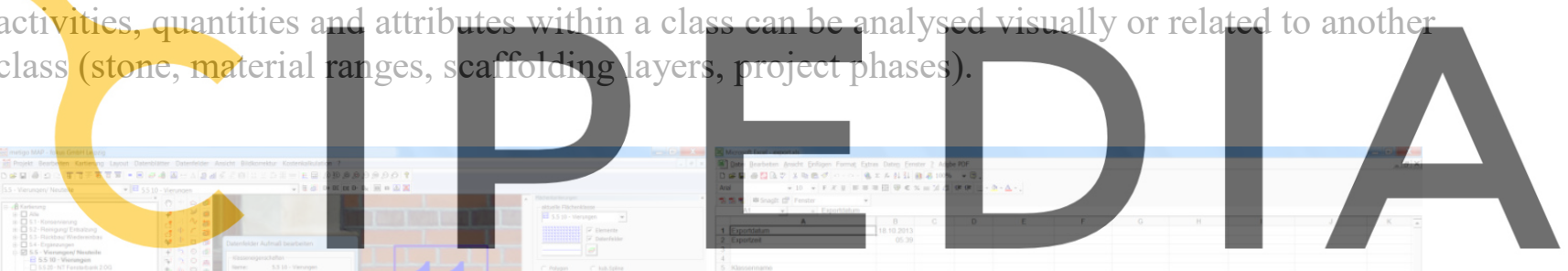

free

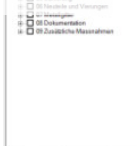

Fig. 7: left: Mapping with manual measurement; right: Quantity export to spreadsheets; District Court, Zwickau, Germany; Mapping: Jens Kaminsky, Plauen.

metigo ${ }^{\circledR}$ MAP allows a user management for analysing the mapping history (querying users, creation and modification dates) as well as a rights management to protect mapping elements of third parties (e. g. loan systems, project phases).

Several approaches for computing areas (mapped polygon, bounding box, manual measurement) are available and individual attributes for recording of object properties (measurements, findings, technological information of the measure) can be used.

Quantity tables can be exported sorted by classes or groups (CSV, MS Excel, Open Office) (Fig. 7). The mapping can be exported in a true-to-scale image (TIFF, multi-layer-TIFF) or CAD-file (DWG) as well as print-out and PDF-file (external PDF-printer). 


\subsection{Object hierarchy}

The object hierarchy offers the management and adjusting of several mapping projects in one object. Therefore a central mapping project with mapping classes, groups, attributes, legends and title blocks is used as mapping template. Each mapping project within an object hierarchy is connected to that template. A later modification, e.g. of colours or names, can be transferred automated on the involved mapping projects.

The hierachy allows the output of quantity tables across projects (CSV, MS Excel, Open Office). The project comprehensive usage of title blocks with variable entries reduces time for creation of title blocks. The user can navigate in object hierarchies via project tree or navigation maps. Using navigation maps, he can execute visual quantity analysis of mapping contents and project attributes (Fig. 8).

The class analysis via complete object hierarchies (mapping contents, class and group structure) allows also the resolving of similar class names, wrong class types or duplicates.

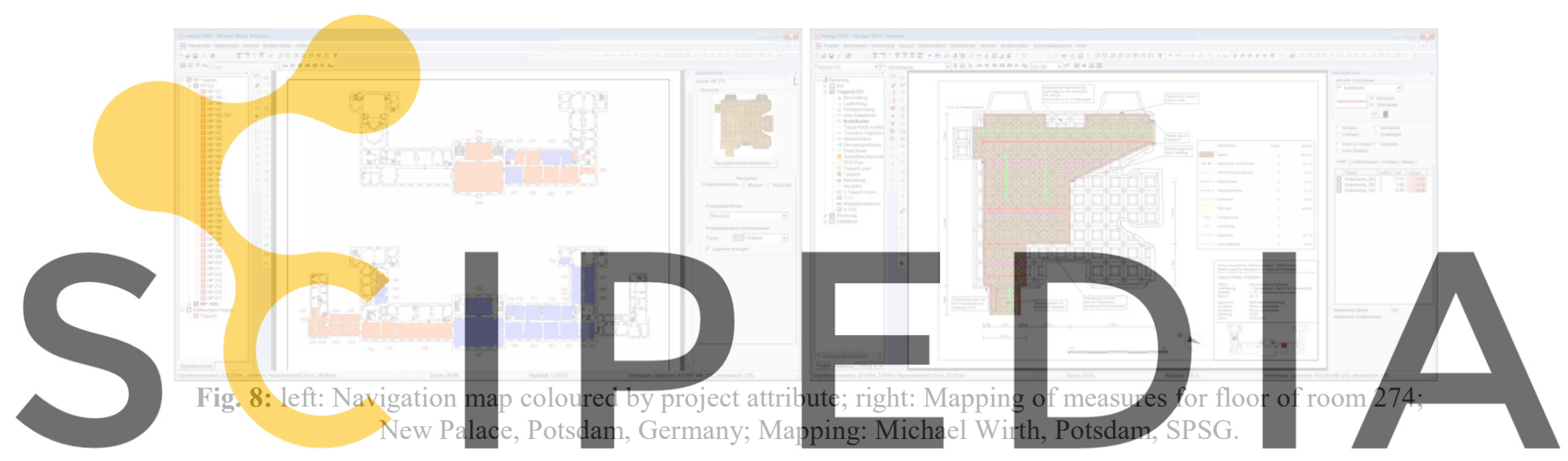

Register for free at https//www.scipedia.com to download the version without the watermark 3 CURRENT RESULTS FROM THE R\&D PROJECT, "PROQUATO"6

The main usage of the mapping software is currently mapping on the base of two dimensional mapping bases. Current development tasks for 3D evaluation are described in the chapters 3 and 4. In the R\&D project PROQUATO ("process optimization, quality enlargement and evaluation tools for multi textured surface models") requirements for 3D mapping were analysed and developed in cooperation with the clients from 2016 to 2018.

\subsection{Data import}

metigo ${ }^{\circledR}$ MAP allows the import of textured surface models in VRML- and OBJ-format or without texture (STL). For mapping, a mesh made of triangles is always required. The import window (Fig. 9, left) allows the insertion of a scaling factor for true to scale import of surface models. Later scaling inside the mapping project is not possible.

Free navigation is possible within the 3D display. Within $2 \mathrm{D}$ display of model views (orthogonal projections), the image data is reduced to the set project scale and resolution. If the textured surface model was created within a defined coordinate system, the congruent combination of orthogonal projection with existing CAD plans is possible (Fig. 10). 

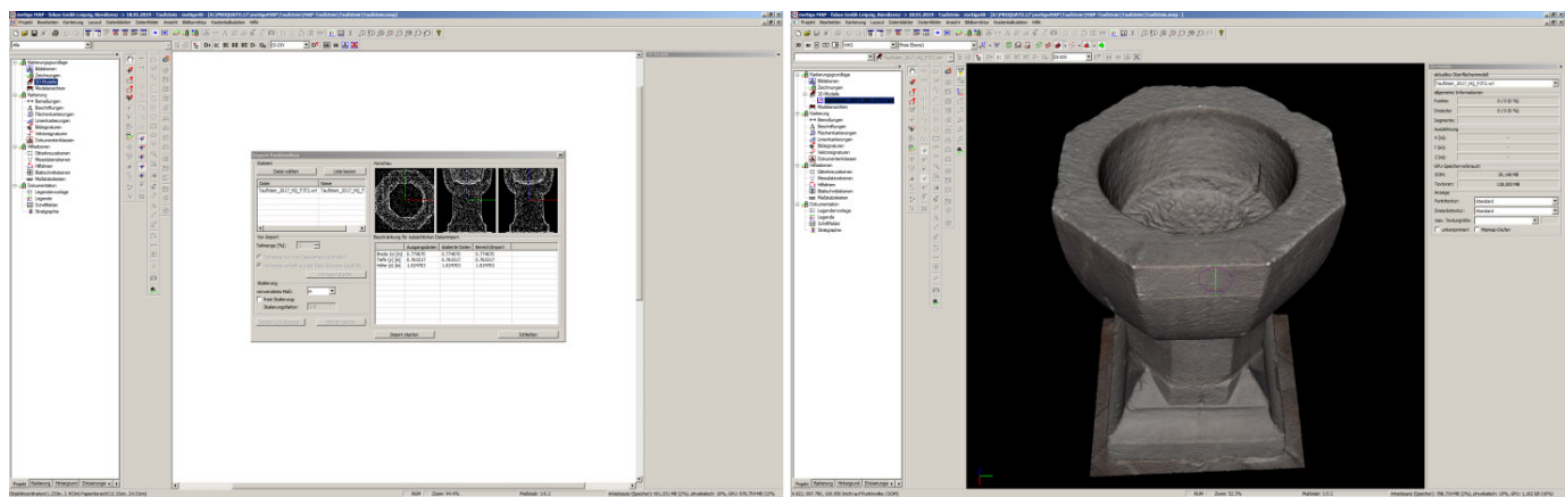

Fig. 9: left: Import window for surface model in STL-, VRML- and OBJ- files with insertion of scaling factor and unit; right: 3D display of textured surface model; Baptismal font, church Kuehren, Germany

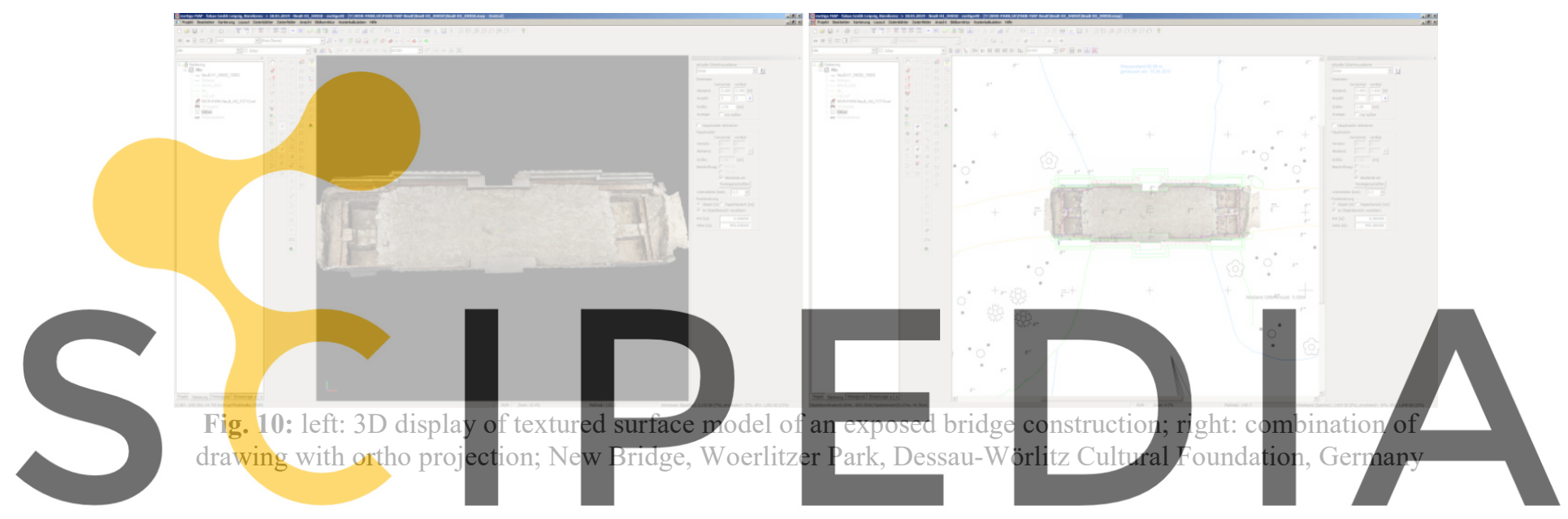

\subsection{Combination of several surface models into one coordinate system}

Register for free at https/fwww.scipedia.com to downdoad the version without the watermark performance of the 3D display predominantly relies on the characteristics of the graphic card.

If the hardware is powerful enough, several models within one coordinate system can be evaluated together.

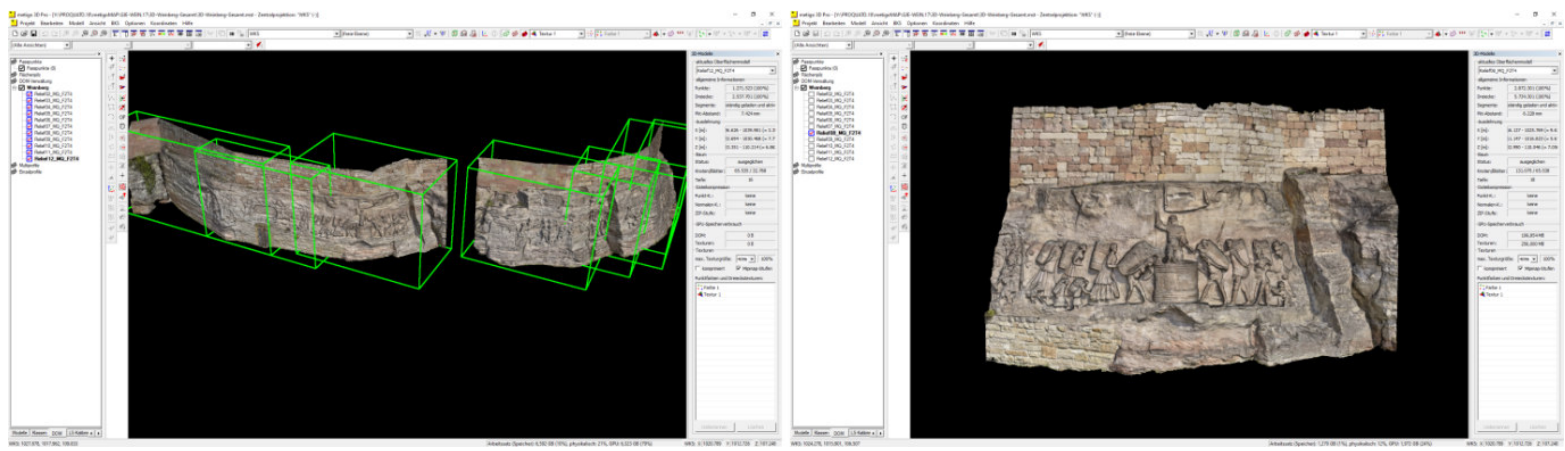

Fig. 11: Mosaic of several textured surface models of one object within one coordinate system, left: Every surface model is displayed with its bounding box (green); right: Single textured surface model; Stone Album, Großjena, Germany 


\subsection{Evaluation of complex surface models by model segmentation}

If the surface model is too big for the used hardware, it is possible to evaluate only segments of the complete surface model. Segmentation allows partial loading of the surface model (Fig. 12). At the start the user can load the surface model in reduced resolution as complete point cloud to define segments, e.g. single parts of a façade. Later, only the required segments need to be loaded.

For complex objects such as sculpture, it is useful to create individual segments e.g. for arms, legs, hands, because it is easier for navigation and makes evaluating obstructed areas (e.g. between an arm and the torso) much easier.

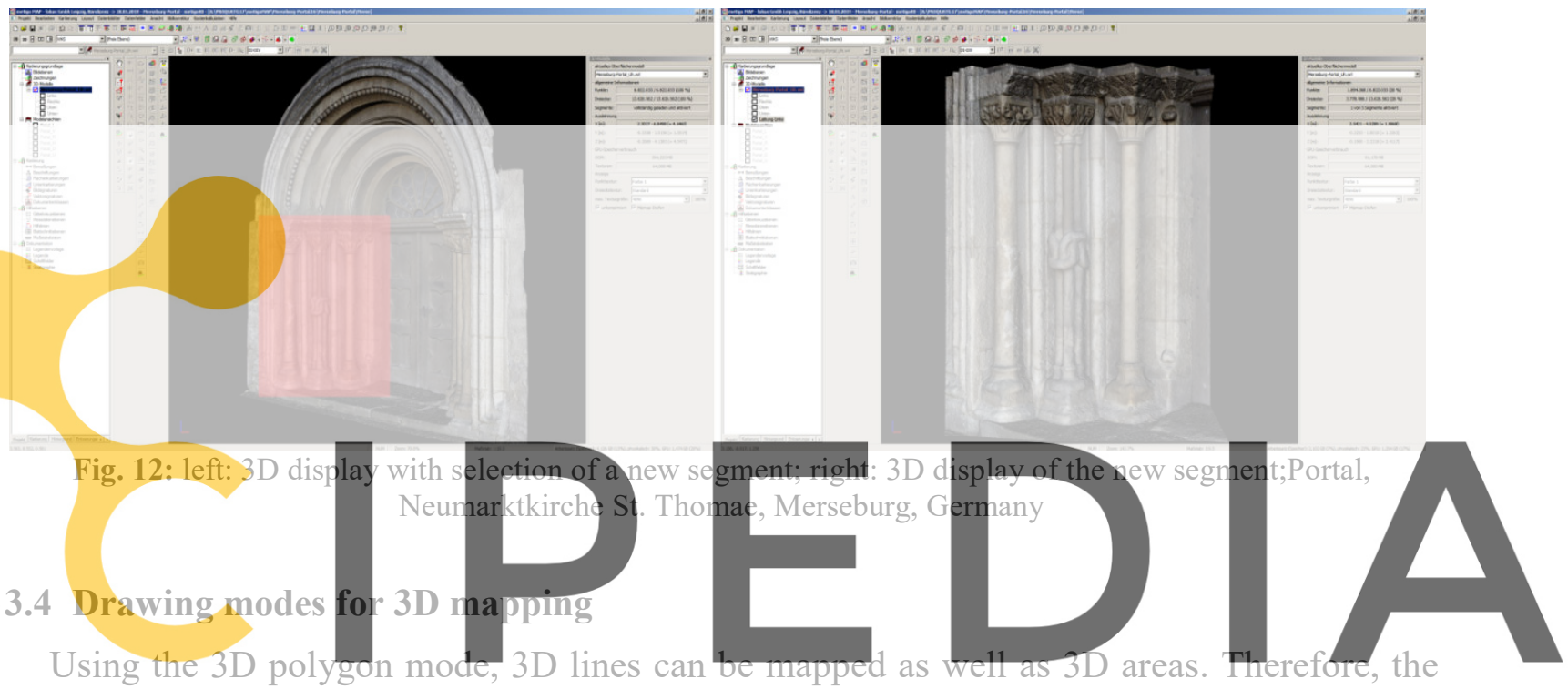

drawn polygon is intersected with the surface model and the result stored as individual 3D

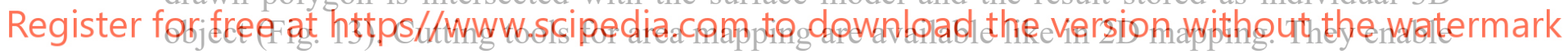

a later extension or reduction of mapped areas as well as the custom-fit cutting of adjoining

areas. Additionally vector symbols or text elements can be used. Border lines and transparent area fillings can be shown in the 3D display. Hatching is visible in 2D / 3D views (Fig. 14).
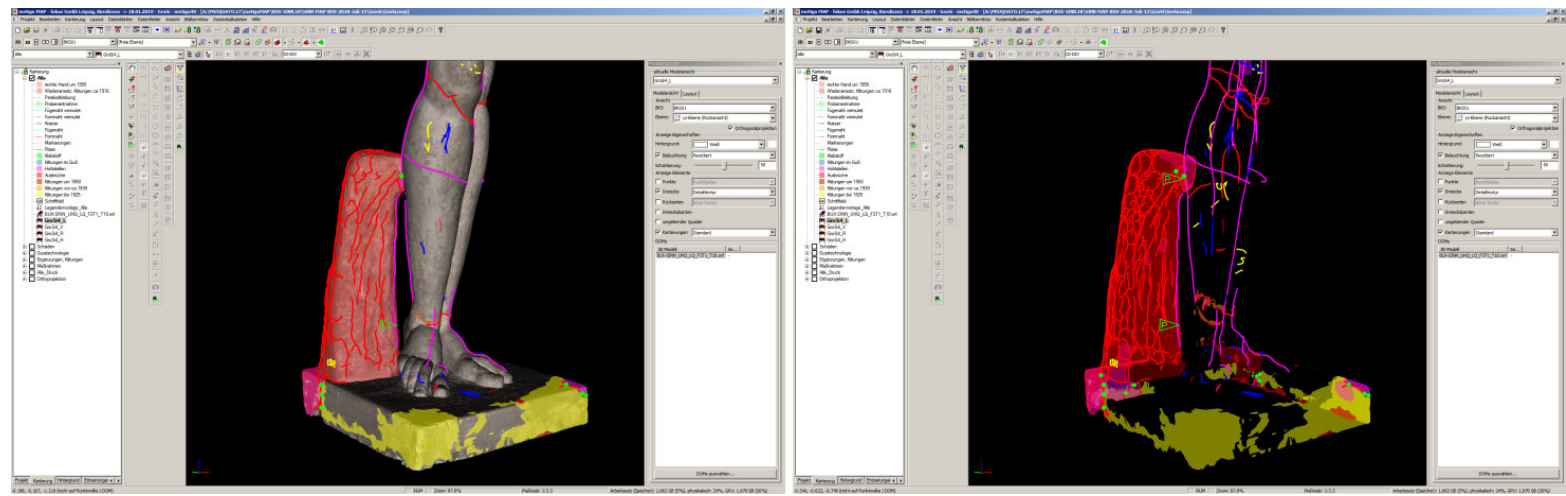

Fig. 13: 3D display; left: textured surface model and mapped elements; right: 3D mapped elements without surface model; Große Sinnende, Wilhelm Lehmbruck, Staatsgalerie Stuttgart; Mapping Peter Bux, Leipzig 

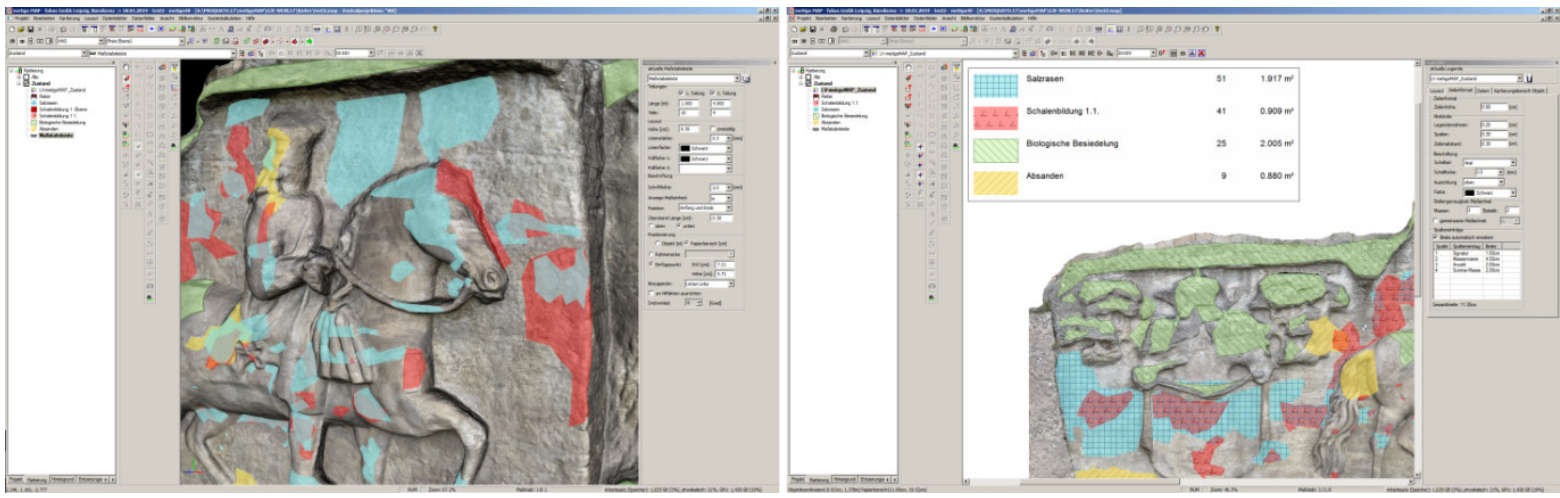

Fig. 14: left: 3D display of area mapping with transparent filling; right: Hatching on 2D model view with orthogonal projection and legend; Stone Album, Großjena, Germany; Mapping: Benjamin Huebner, Potsdam

\subsection{Printing with the help of 2D model views}

A true to scale 2D model view of the chosen 3D display can be created to be used for 2D printouts (Fig. 15). Display options like texture quality, shading, scale and position as well as projection mode (orthogonal/perspective) can be set up.
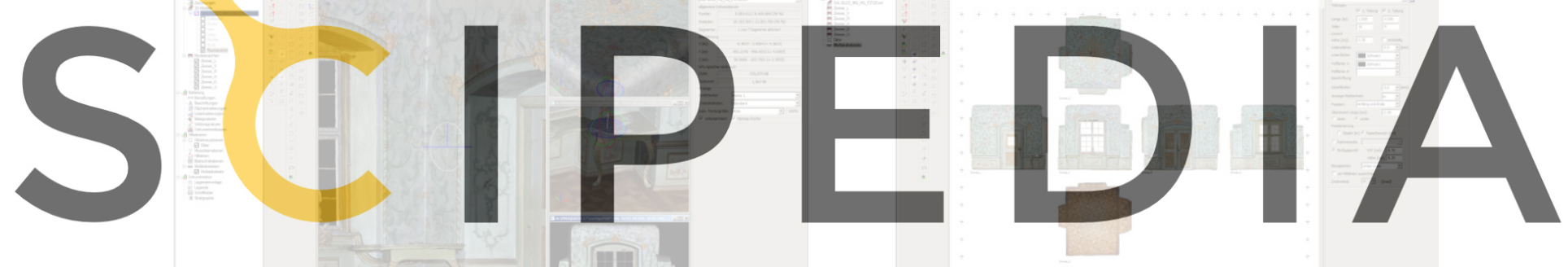

Register for free at https//www.scipedia.com to download the version without the watermark

Fig. 15: left: 3D display of textured surface model of the room; right: true to scale inside unwrapping of 6 model views with orthogonai projection; Abbot's quarters, Castie Salem, Salem, Germany

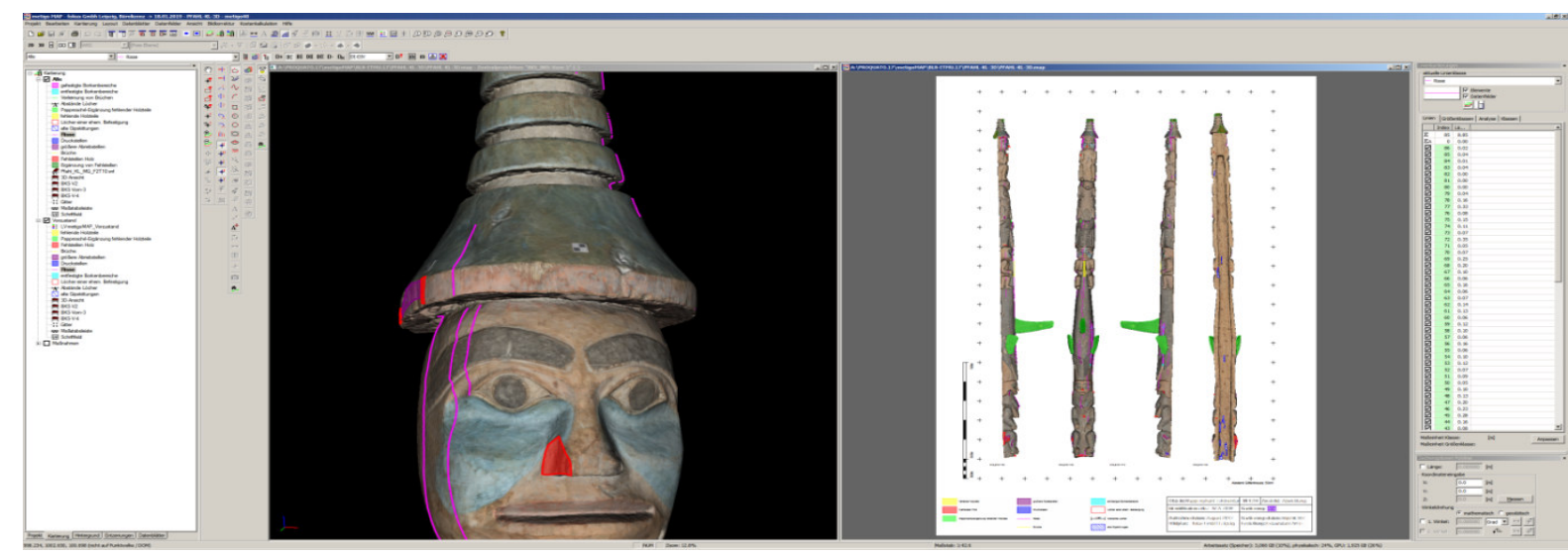

Fig. 16: left: textured DSM of the totem pole with mapping; right: True to scale unwrapping of 4 model views with orthogonal projection; Totem Tshimshian, Ethnological Museum, Berlin; Mapping: restauratum ArGe 
Automated creation of "model view unwrapping" (inside/outside; 4 or 6 orthogonal views) allows a complete display of the object (Fig. 15, 16). The plan can be completed by inserting grid crosses, scale bar and title block. The 3D display can be controlled like the 2D model views, using mapping groups and group legend (Fig. 16). The true to scale printing or image output is carried out in the same way as $2 \mathrm{D}$ mapping. Currently the $3 \mathrm{D}$ mapping can only be passed on as complete mapping project with a free viewer.

Quantity measurement is determined automatically based on the true to scale surface model. So the amount, length and areas of mapped elements are calculated immediately and the sum can be shown within the legend for each class. If the total amount of the object is mapped, the mass fraction for each area mapping class can be shown in the legend (Fig. 17)

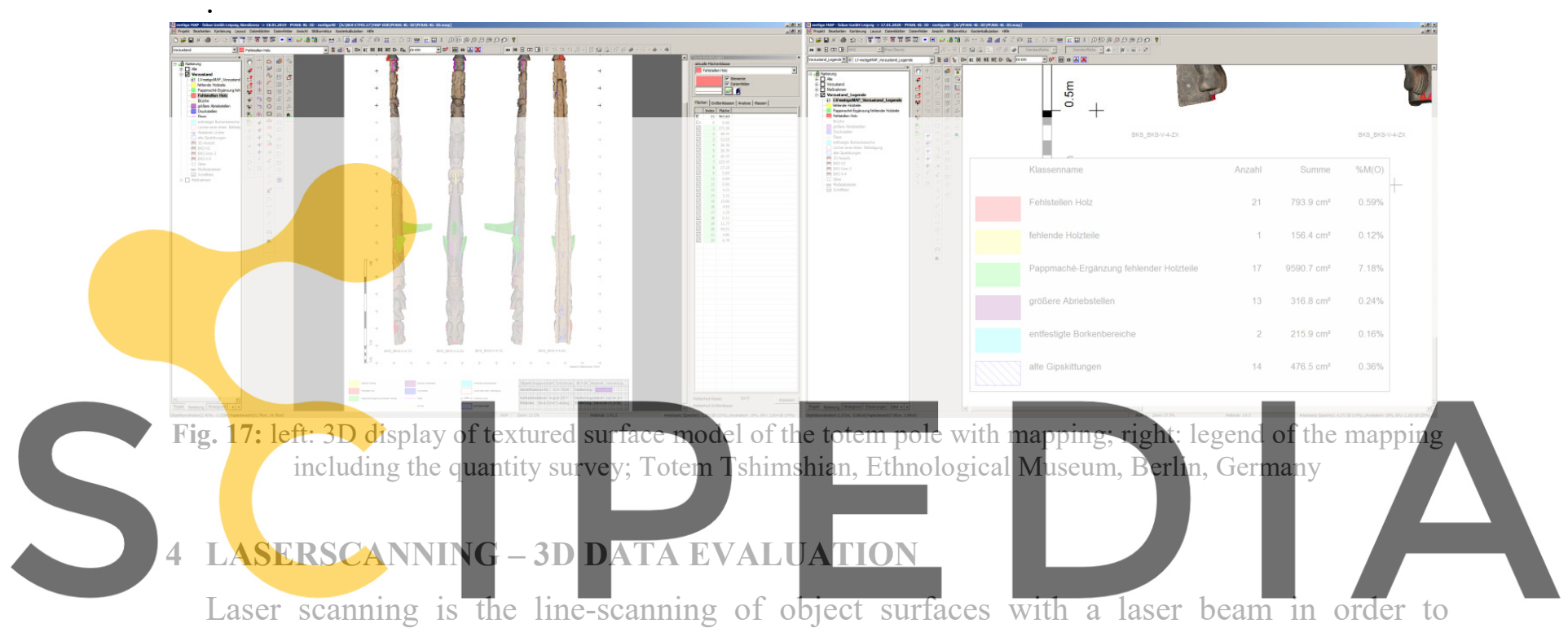

Register measure it three-dimensionally. The result is a three-dimensional point cloud grey scaled fepene art https dww sw scipediaicond to downlead the version without the watermark

with real object colour. With a suitable orientation software, the individual point clouds are automatically oriented in a uniform coordinate system. The so oriented point clouds can be used as base for CAD-evaluation of floor plans, sections and elevations.

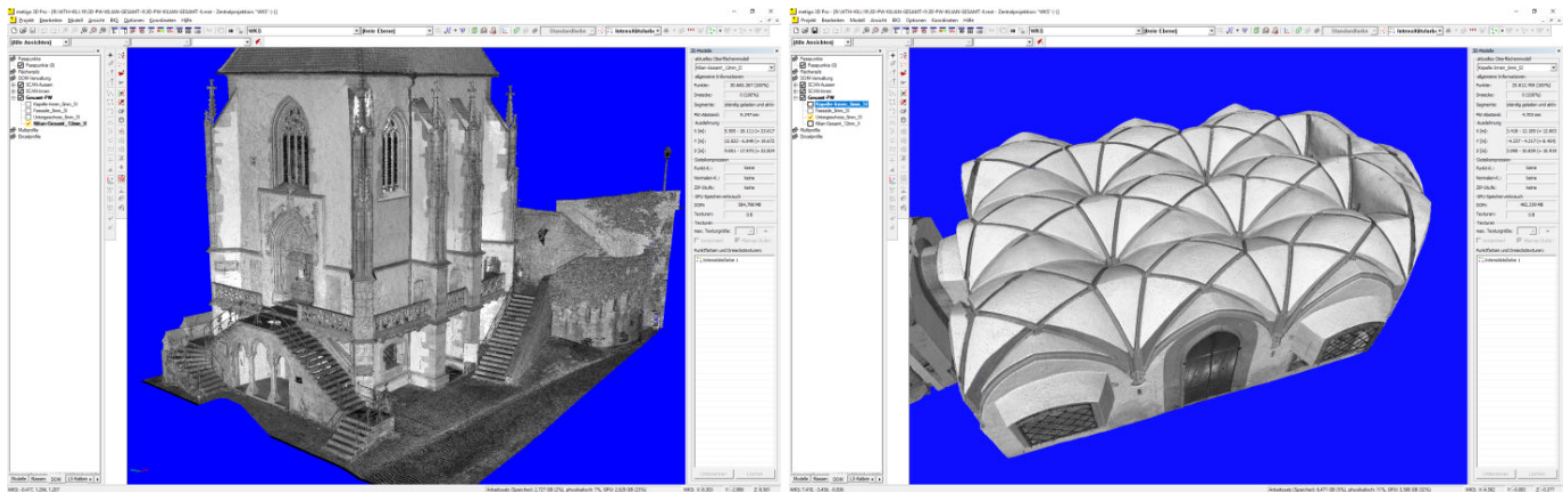

Fig. 18: left: 3D view of the complete point cloud; right: 3D view of the basement; St. Killian`s Chapel, Wertheim upon Main, 


\subsection{D data processing}

In metigo ${ }^{\circledR} 3 \mathrm{D}$ software, the oriented point clouds of the individual scanner positions can be merged to an object point cloud / complete point cloud with a defined point distance. The quality of the resulting point cloud can be controlled by using functions to filter noise depending on intensity, position or recording angle (Fig. 18).

\subsection{D data evaluation}

To evaluate $3 \mathrm{D}$ data the complete point cloud is needed within metigo ${ }^{\circledR}$ MAP. Point clouds can be imported in a metigo ${ }^{\circledR}$ internal format (*.SHP) or standard formats like E57, PTS, PTB. Selection polygons can be used to create partial point clouds as base for creation of orthogonal projections. Settings for shading, lighting and closing of holes in the orthogonal projection allow the quality enhancement of the final result (Fig. 19).

Defining user coordinate systems section lines with a tolerance distance can be extracted from the point cloud automatically. These section lines can be used for the creation of CAD drawing in 2D or 3D (Fig. 20).

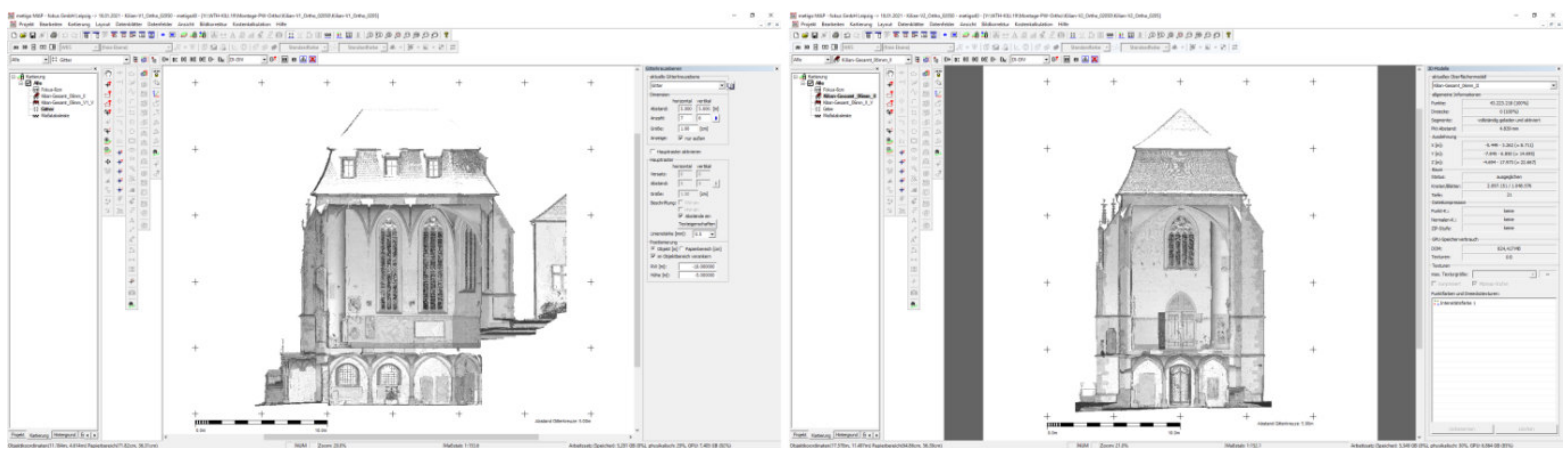

Fig. 19: Different Ortho-projected sections of the point cloud (left: longitudinal; right: latitudinal); St. Killian's Chapel, Wertheim upon Main,

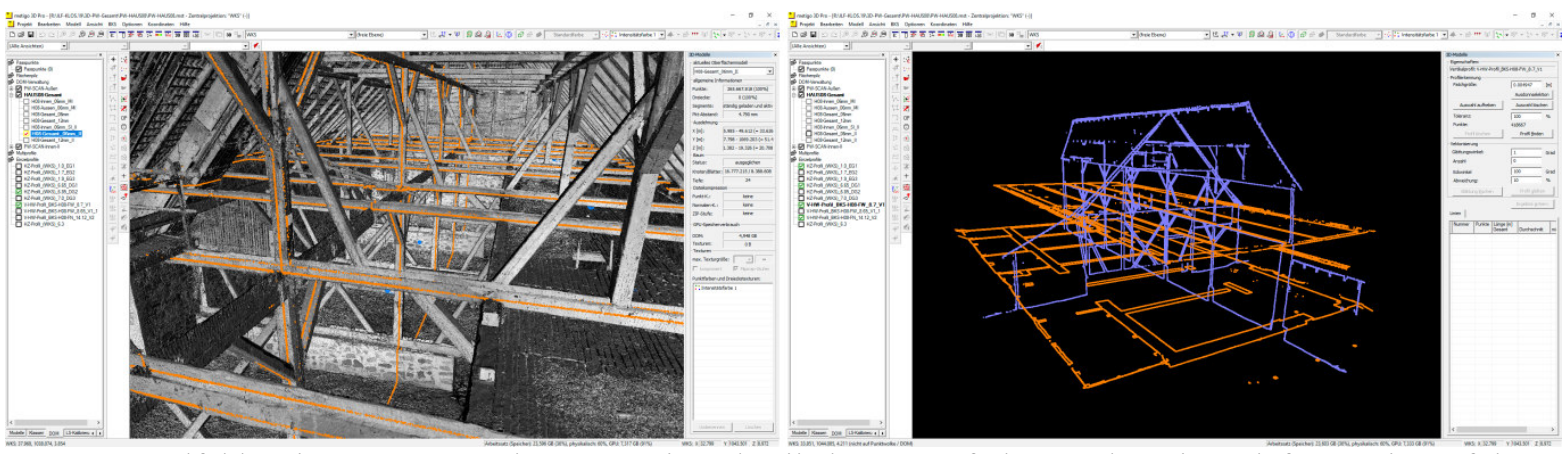

Fig. 20: Ilfeld, Priory Manor.3D laser scanning, detailed survey of plans and sections. left: 3D view of the complete point cloud with coloured section planes (longitudinal and horizontal section); right: 3D view only of the coloured section planes; monastery estate, Ilfeld, Germany 


\section{SUMMARY}

The procedures described allow the true to scale documentation on the base of $2 \mathrm{D}$ or $3 \mathrm{D}$ data, assuming the quality of the 3D data is sufficient to the object requirements. In this way several 3D documentation projects have been processed. But in our experiences there is often a lack of accuracy and detail resolution - image texture or the point cloud - especially if the 3D data is used as working base in conservation documentation. Many 3D documentation results are created currently by third parties, that have no information or knowledge about the needed requirements.

The software metigo ${ }^{\circledR}$ MAP is developed in the past 20 years in close cooperation with our customers to their special needs - at the beginning in the field of digital 2D mapping and later in quantity survey and data analyses. In future there will be additional developments in the field of 3D evaluation, depending on the needs of our users. So the step from two dimensional to three dimensional evaluation is now possible, depending on the quality of the $3 \mathrm{D}$ data, the requirements of the project and the existing hardware.

\section{REFERENCES}

[1] Siedler, G. and Sacher, G.: Photogrammetrische Auswertung historischer Fotografien und Messbilder. In: Führerauftrag Monumentalmalerei, Veröffentlichungen des ZIKG, Band XVIII, 2006, Böhlau Verlag GmbH \& Cie, S.189-198.

[2] Vetter, S. and Siedler, G., Automated 3D-object documentation on the base of an image set. 13. International CIPA Symposium, Prag (Tschechische Republik), 2011

[3] Siedler, G. and Vetter S., Modern Methods of documentation - Photogrammetric evaluation of historic images. ICOM CC - Interim Meeting of the Wood, Furniture, and Lacquer \& the Sculpture, Polychromy, and Architectural Decorations Working Groups in Potsdam, Germany, 2016

[4] Siedler, G. and Vetter S., Qualitätskriterien bei der Ausschreibung von photogrammetrischen Leistungen. Natursteinsanierung Stuttgart 2018 - Neue Natursteinrestaurierungsergebnisse und messtechnische Erfassungen sowie Sanierungsbeispiele, Stuttgart, Germany, 2018

[5] Luhmann, T., Nahbereichsphotogrammetrie - Grundlagen, Methoden und Anwendungen. Verlag für Bauwesen, Berlin, Germany, 1978

[6] W. Pietschner, J. Regensburger, K. Rüger, Photogrammetrie. Verfahren und Geräte. Herbert Wichmann Verlag, Heidelberg, Germany, 2003

[7] Brumana R. and Galeazzo, G.; St. Marcus' Basilica in Venice. An apply of image projection on a dome. XVII ISPRS Congress Technical Commission V: Close-Range Photogrammetry and Machine Vision, page 786-793, Washington, D.C., USA, 1992

[8] Stephani, M.; Object Modelling and Visualization in Architecture. XVII ISPRS Congress Technical Commission V: Close-Range Photogrammetry and Machine Vision, page 821824, Washington, D.C., USA, 1992

All shown examples are documentation projects processed by fokus GmbH Leipzig, otherwise the author is named in the belonging caption. 